\title{
Augmented Reality Supported Cervical Transpedicular Fixation on 3D-Printed Vertebrae Model: An Experimental Education Study
}

\author{
Mehmet Gazi BOYACI ${ }^{1}$, Ugur FIDAN²${ }^{2}$, Ahmet Fatih YURAN², Serhat YILDIZHAN ${ }^{1}$, Furkan KAYA ${ }^{3}$, \\ Omer KIMSESIZ4 ${ }^{4}$, Merve OZDIL ${ }^{4}$, Akın CENGIZ1 ${ }^{1}$ Adem ASLAN ${ }^{*}$

\begin{abstract}
${ }^{1}$ Afyonkarahisar Health Sciences University, Faculty of Medicine, Department of Neurosurgery, Afyonkarahisar, Turkey ${ }^{2}$ Afyon Kocatepe University, Faculty of Engineering, Biomedical Engineering, Afyonkarahisar, Turkey

${ }^{3}$ Afyonkarahisar Health Sciences University, Faculty of Medicine, Department of Radiology, Afyonkarahisar, Turkey

${ }^{4}$ Afyonkarahisar Health Sciences University, Faculty of Medicine Undergraduate Student Member, Afyonkarahisar, Turkey
\end{abstract} \\ *Senior Author
}

Corresponding author: Mehmet Gazi BOYACl mgazibyc@hotmail.com

\section{ABSTRACT}

AIM: To investigate the use of Augmented Reality (AR) technology as it contributes to spinal surgery education with the free-hand technique, and might reduce the error ratio.

MATERIAL and METHODS: Ten candidates, with anatomy education but no surgical experience, applied 36 pedicle screws with C2-C3 posterior transpedicular fixation technique to nine vertebrae models produced via a three-dimensional (3D) printer.

RESULTS: Using AR to apply pedicle screws to the experimental vertebrae model increased the safety screw ratio significantly. In comparison of Grade 0 screws to other grades: 6/18 screws (33.3\%) in the free-hand technique Group ( $n=18)$, and 14/18 screws $(77.8 \%)$ in the AR Group $(n=18)$, were measured for screw insertion safety ratios. The difference was statistically significant $(p=0.018)$. The resemblance between our results and the results of previous studies researching supportive systems indicates our $3 \mathrm{D}$ printed vertebra model might be a helpful educational material.

CONCLUSION: AR increases the safety ratio of cervical pedicle screw fixation significantly. The parameters investigated and used for the production of vertebrae models in this study can be used for experimental material production for future studies to investigate pedicle screw positioning.

KEYWORDS: Augmented reality, Pedicle screws, Posterior instrumentation, Upper cervical spine fracture

ABBREVIATIONS: 2D: Two-dimensional, 3D: Three-dimensional, AR: Augmented reality, FH: Free-hand, PACS: Pictures archiving and communication system

Mehmet Gazi BOYACI (10): 0000-0001-7329-2102

Ugur FIDAN $\quad$ (1): :0000-0003-0356-017X

Ahmet Fatih YURAN (D): 0000-0002-2105-2614
Serhat YILDIZHAN (1) : 0000-0001-9394-5828

Furkan KAYA (D) : 0000-0001-8619-7593

Omer KIMSESIZ (1) : 0000-0001-7008-536X
Merve OZDIL (1) : 0000-0001-7555-230X

Akın CENGIZ (D) : 0000-0002-8798-6495

Adem ASLAN (1) : 0000-0003-2269-9417 


\section{- INTRODUCTION}

T Transpedicular screw fixation is widely used due to its successful fixation of the three vertebrae columns $(10,24,26)$. Vertebrae integrity, the spinal cord, and the vascular structures can only be seen through a semi-open incision during spine surgery and this makes the implantation surgery a procedure requiring talent and experience (26). Neurovascular structures can become severely injured because of transpedicular screw malposition $(5,6,11)$. The success rate of conventional techniques for $\mathrm{C} 2$ pedicle screw necessitates serious supportive systems $(2,10,21,26)$.

With regards supportive systems, navigation systems that work by fusion of anatomic signs, intraoperative imaging, and $\mathrm{CT} / \mathrm{MRI}$ images, are becoming increasingly important. However, none of the traditional techniques are accepted as intraoperatively perfect supportive methods since none provide the accuracy required for applying pedicle screws (24). The traditional method of spinal instrumentation surgery requires the surgeon to synthesise the pre-operative fluoroscopy, CT, and $\mathrm{MRI}$ images with restricted anatomic visualisation and relies on the analytical thinking capability of the surgeon (9). Practical experience, besides anatomic and biomechanical information, is also necessary to apply a successful screw. Not every clinic provides the required amount of patients to gain experience for upper cervical surgery training, and cadaveric studies remain limited (23). The surgeon's educational and surgical experience is still crucially important. Therefore, technological innovations should be integrated into educational processes to enhance the quality of educational experience.

Augmented Reality (AR) is a technology that allows computergenerated virtual imagery information to be overlaid onto a live, direct or indirect real-world environment in real time (16, $27)$. In other words, AR simply allows the user to manipulate real-world environment scenes using virtual imagery (3). AR may allow for the integration of technology with educational processes. Three-dimensionally (3D) printed vertebrae models designed with patient CT images may provide experience to fellow surgeons and improve their abilities (12).

Our study investigates the improvements in screw insertion safety ratios of free-hand techniques supported by $A R$, while applying pedicle screws to 3D-printed vertebra models, and the possible outcomes to spinal surgery education.

\section{MATERIAL and METHODS}

This study was carried out with the decision dated 05.01.2018, and numbered 2018/1-28 by Afyon Kocatepe University Clinical Research Ethical Board. Ten candidates (physicians and medical students with medical education but no surgical experience) were divided into two groups of five. Both groups were briefed on the free-hand $(\mathrm{FH})$ technique from resource journals $(18,25)$. Each group applied 18 pedicle screws to nine vertebrae models. In total, 36 pedicle screws were applied to nine unique vertebra models created by $3 \mathrm{D}$ printers exclusively for this study (Figures 1A-D; 2A-C).

\section{Choosing the Experimental Vertebrae Model}

The Neurosurgery Clinic archives at our institution were retrospectively researched for cervical CT images. Traumatic spondylolisthesis was chosen as an experimental model for C2-C3 pedicle screw insertion due to the procedure's rarity and difficulty (4). Nonetheless, the anatomic position and vertebra's landmarks remain still after reduction of the fracture. According to this information, a normal vertebra image was chosen to compare pedicle screw (PS) safety ratios between the $\mathrm{FH}$ technique and $\mathrm{AR}$, independent from reduction and/ or manipulation variables. A patient who had a cervical CT due to trauma, with normal radiological findings such as normal pedicular structure and cervical arrangement, was selected. The review was completed with a Toshiba Aquilon Multiplan CT Machine (Toshiba Medical Systems, Japan) at the Department of Radiology CT Unit. For axial plans, 1-mm thin slices were taken. For all cases, in addition to the axial plane, coronal and sagittal reformatted images were created. These images were transferred to the 'Pictures Archiving and Communication System' (PACS) (Enlil - Eroglu, Eskisehir), where window settings, magnification, and scaling could be done. All images were interpreted by experienced radiologists and neurosurgeons at workstations connected to the PACS.

\section{Process of the Production of the Vertebrae Models via a 3D Printer}

The cervical CT and DICOM slice images of the earlier chosen patient were transformed into 3D models with the Mimics ${ }^{\circledR}$ 13.0 and 14.01 software package (Materialise, Plymouth, MI, USA). The STL model files were transferred to RepetierHost $^{\circledR}$ slicing software (Willich, Germany) and transformed into G-code files. Fused Deposition Modelling (1) was used for printing. Subsequently, the vertebrae were printed for material examinations. Nine vertebrae models were produced according to the parameters (Table I) developed and defined by collecting feedback from experienced neurosurgeons.

\section{AR Process}

$\mathrm{AR}$ is a technology that allows computer-generated virtual imagery information to be overlaid onto a live, direct or indirect real-world environment in real time $(16,27)$. AR requires a realworld object, called a tracker, to identify the scene. QR codes are two dimensional barcodes, produced for machine reading and identification. In AR systems, QR codes are used as tracker materials for the device to identify the environment and overlay the virtual imagery over the real-environment scene.

In this study, the AR system was built with every day use mobile devices and a QR code used as tracker material. The application's user interface was created with The Unity ${ }^{\circledR}$ Software (San Francisco, United States) and the database, which contains the virtual 3D image and links it to the QR code, was created on the Vuforia ${ }^{\circledR}$ database system.

The virtual 3D model files previously used to produce the printed vertebrae were also uploaded to the Vuforia ${ }^{\circledR}$ database and linked to its specific tracker in The Unity ${ }^{\circledR}$ software. During the creation of the virtual imagery process in Unity ${ }^{\circledR}$, with the assistance of experienced surgeons, virtual screw trajectories were applied to the virtual model to assist the candidates in applying the screws to the printed vertebra model (Figures 3, 4). 

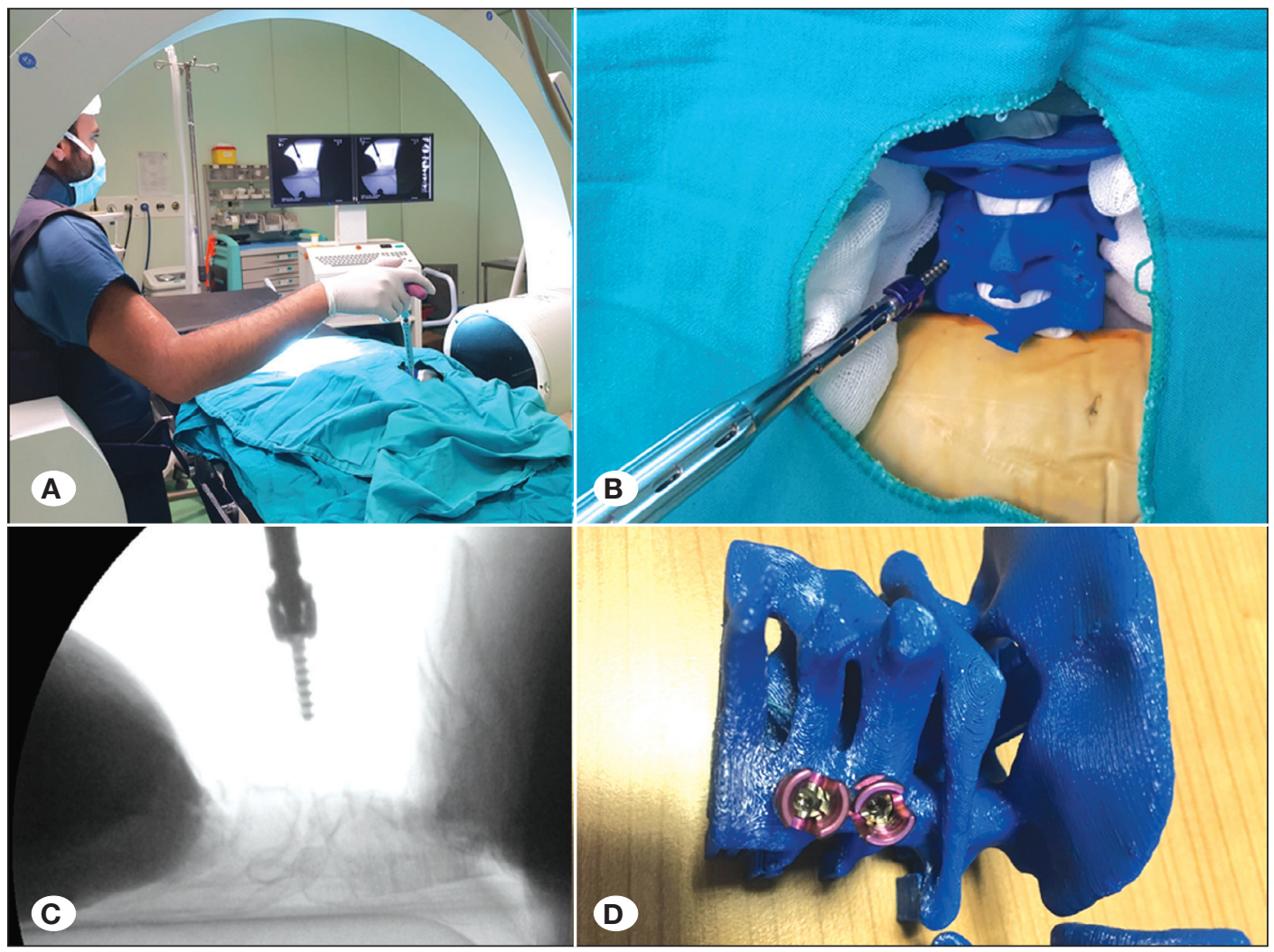

Figure 1: A) Fluoroscopy supported screw application to the C3 vertebrae. The surgeon is arranging the insertion point, angle, and length. B) Repeated fluoroscopy imaging during the screw application to the C3 vertebra.

C) Screw application to the vertebrae model, simulated with dura mater material in order to block the view of the structures that provide anatomic orientation.

D) After the screw application to the $\mathrm{C} 2$ and C3 vertebra models produced via the $3 \mathrm{D}$ printer.

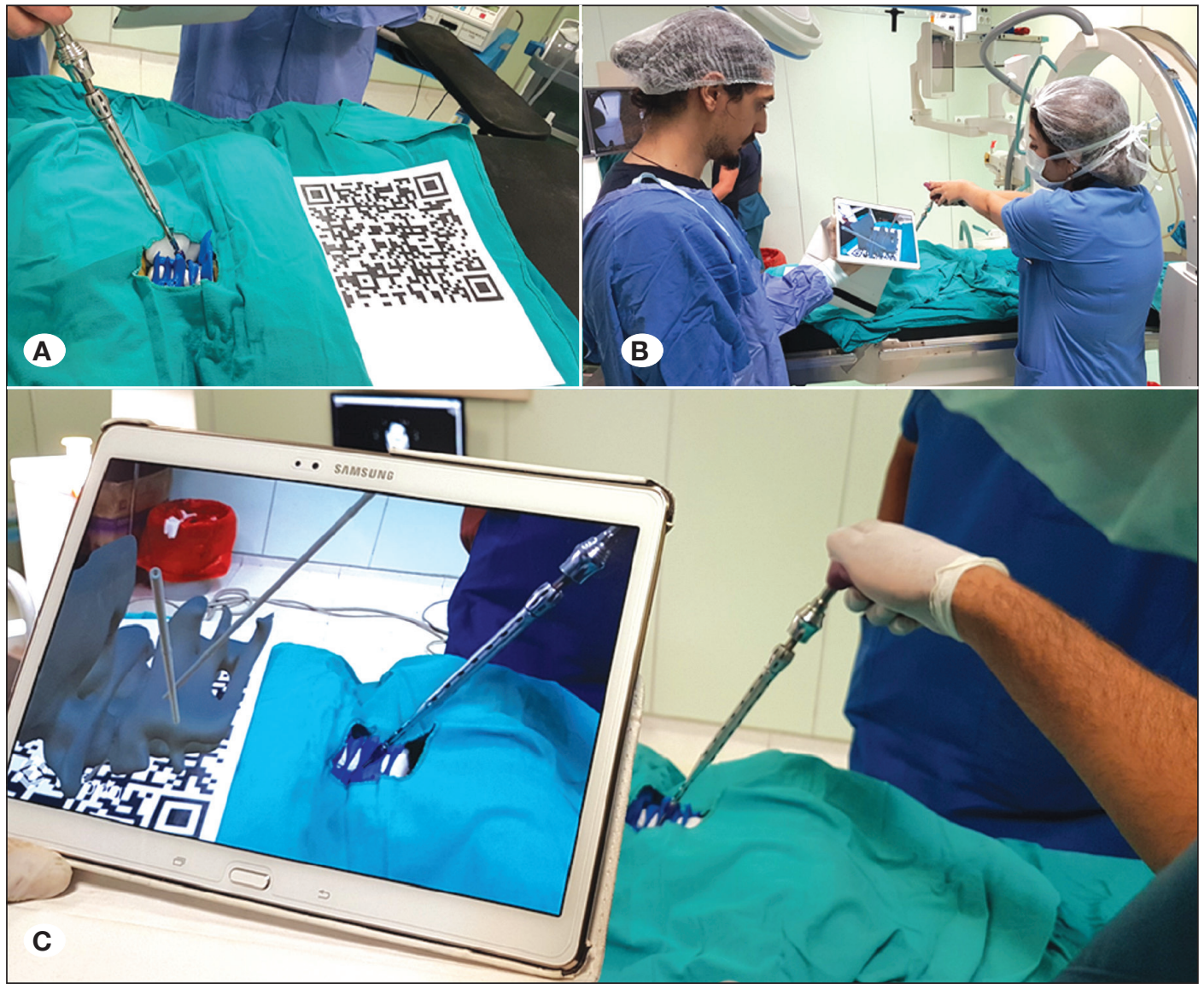

Figure 2: A) Use of augmented reality (AR) during pedicle screw application to C2 vertebra. B) The candidate's view of the AR model tracks, and arrangement of the insertion point via a tablet PC during pedicle screw application to the C2 vertebra. The tablet personel computer (PC) is held at the appropriate angle by an assistant. C) Candidate's track arrangement via AR on tablet PC during pedicle screw application to the C2 vertebra. The tablet PC is held at an appropriate angle by an assistant. The C2 AR track and pedicle screw tool parallel on the tablet screen. 
Boyaci MG. et al: Augmented Reality \& Transpedicular Fixation

Table I: The Parameters of the 3D Printed Vertebrae Model

\begin{tabular}{lc}
\hline Parameter & Value \\
\hline Print Volume, mm & $300 \times 300 \times 275$ \\
\hline Filament Thickness, $\mathrm{mm}$ & 1.75 \\
\hline Filament Type & PLA \\
\hline Nozzle Diameter, mm & 0.4 \\
\hline Melting Temperature, ${ }^{\circ} \mathrm{C}$ & 210 \\
\hline Bottom Layer Temperature, ${ }^{\circ} \mathrm{C}$ & 25 \\
\hline Environment Temperature, ${ }^{\circ} \mathrm{C}$ & 20 \\
\hline Wall Thickness, mm & 1.3 \\
\hline Layer Thickness, mm & 0.200 \\
\hline Gap Ratio, $\%$ & 40 \\
\hline Inner Inlay Structure & Honeycomb \\
\hline PLA: Polylactic acid polyester.
\end{tabular}

PLA: Polylactic acid polyester.

\section{Application of Pedicle Screws to Vertebrae Models}

In this study, C2-C3 transpedicular screw fixations, as indicated for Hangman's fractures, were researched. Ten surgically inexperienced candidates were briefed on the $\mathrm{FH}$ technique from resource journals $(18,25)$. Thirty-six EF Spine ${ }^{\circledR}$ (Izmir, Turkey) $3.5 \times 30-34 \mathrm{~mm}$ pedicle screws and screw fixation tools were provided. Five candidates (Group 1, n=18) fixed 18 screws to nine printed vertebrae models with the $\mathrm{FH}$ technique. Five candidates (Group 2, n=18) applied screws via $\mathrm{AR}$ assistance, in addition to the $\mathrm{FH}$ technique, to the same model's contralateral sides (8).

\section{Review of Pedicle Screws}

Subsequent to PS application, CT imaging was performed on the vertebrae models in the axial and sagittal planes. Each PS was analysed for medial (M) and lateral (L) position; graded as M0, M1, M2, M3, L0, L1, L2, or L3 with Gertzbein Grading $(7,17)$; and scored (5) as follows: $M 0, L 0=$ no malposition, 0 points; M1, L1 = 0-2 mm, mild malposition, 1 point; M2, L2 = 2-4 mm, intermediate malposition, 2 points; M3, L3 = >4 mm,
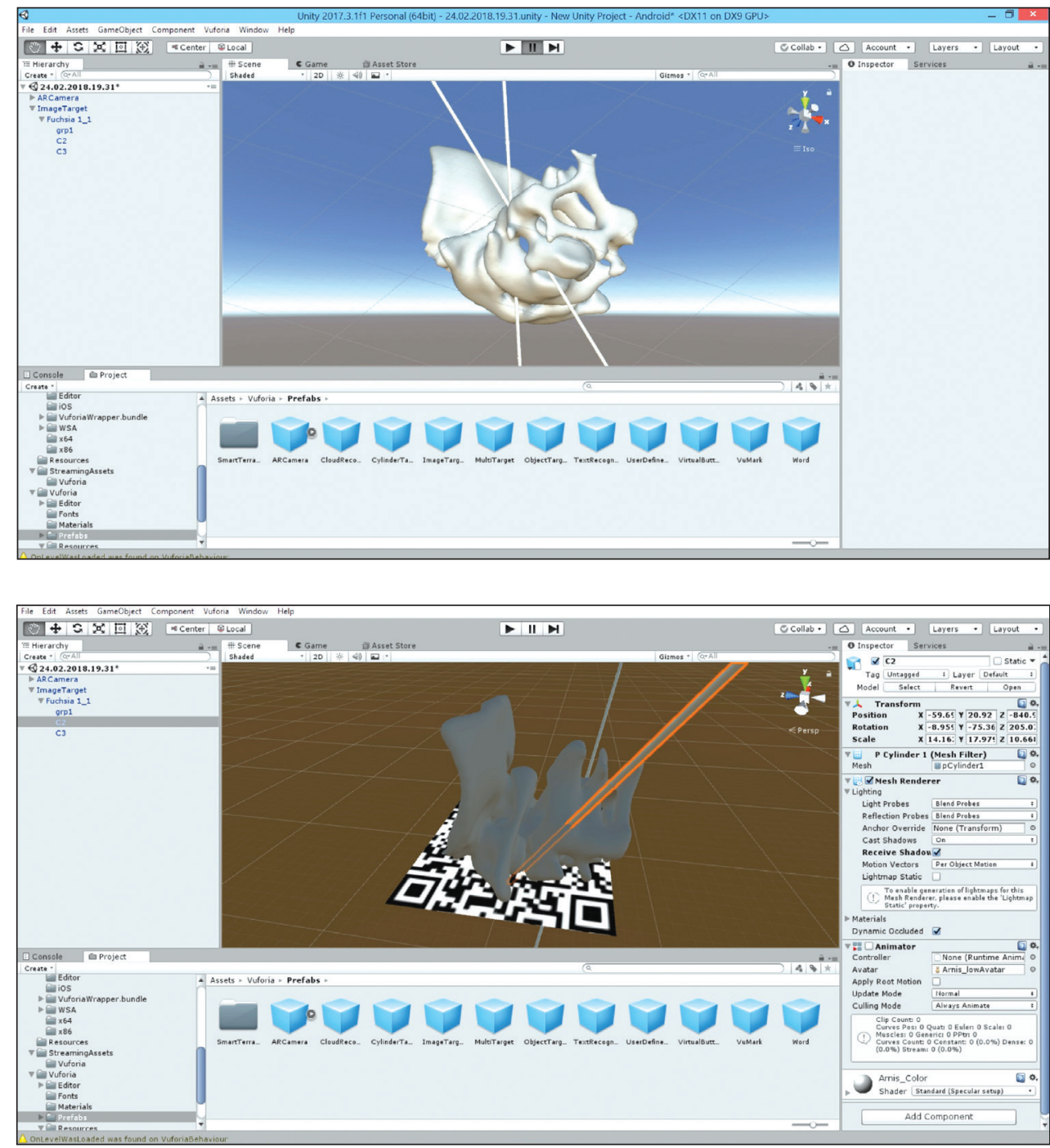

Figure 3: Screenshot of the visual $3 \mathrm{D}$ vertebra model processed from CT images, and preparing the virtual assistance sticks through calculation of perfect screw insertion point and tracks on Unity ${ }^{\circledR}$ Software.

Figure 4: Calibration of virtual 3D model with the tracker material, which will be placed on the surgical area. 
severe malposition, 3 points (Figure 5A-D). In addition, the screws were classified as inside $(M 0, L 0)$ and outside $(M>0$, $L>0$ ). The Kaneyama et al. definition of screw insertion safety ratio (Grade 0/Total) was used for comparison. The percentage of Grade 0 screws to all screws was calculated (10).

\section{Statistical Analysis}

The SPSS 20.0 package software was used for statistical analysis. Groups were compared using the Pearson Chisquare test for categorical data and Fisher's exact test was used for nominal variables comparison. A p-value of $<0.05$ was considered statistically significant.

\section{RESULTS}

In total, 36 pedicle screws were applied to nine 3D printed vertebrae models. Twenty pedicle screws (55.5\%) were measured as Grade 0 and safe in accordance with Gertzbein and Robbins (7), and Kaneyama et al. (10), respectively. This result was accepted as the inexperienced surgeon candidate screw fixation ratio. Fourteen and six screws were observed as Grade 0 in the AR $(n=18)$ and $F H$ technique groups $(n=18)$, respectively.

In comparison of Grade 0 screws to other grades: 6/18 screws (33.3\%) in the FH technique Group $(n=18)$, and 14/18 screws $(77.8 \%)$ in the AR Group $(n=18)$, were measured for screw insertion safety ratios. The difference was statistically significant $(p=0.018)$ (Table II).

\section{DISCUSSION}

Our study indicates that the AR supported $\mathrm{FH}$ technique increases the pedicle screw safety ratio compared to the $\mathrm{FH}$ technique alone. This effect caused by AR might increase the quality of applied training of spinal surgery when a candidate's surgical inexperience is considered.

According to Liu et al. (13), AR guided systems should not be recommended for use in clinical evaluation before significant improvement in the technology. Therefore, in our study, the contributions of AR to screw insertion safety ratio for applied training were instead focused on screw accuracy improvements, which are of more use to define clinical research results.

Ma et al. reported that surgeons can intuitively imagine an AR scene easier than 2D supportive methods (generally fluoroscopy or CT/MRI) (14). Alongside its educational

Table II: Grading of Pedicle Screws and Grade's Distribution

\begin{tabular}{lcc}
\hline PS $(n=36)$ & Grade 0 & Grade 1 \\
\hline Group 1 (FH) (n=18) & 6 & 6 \\
\hline Group 2 (AR) (n=18) & 14 & 2 \\
\hline
\end{tabular}

Group 1 (FH): Free-hand Technique Group, Group 2 (AR): Augmented Reality Group.

*Safety: Presented as the number of Grade 0 screws/total number of screws per group. When safety values compared, Fisher's exact test $p<0.05$. benefits, AR applications are provided at low cost which allows the technology to be widely used, in contrast to similar studies using expensive supportive imaging systems and software which can only be provided by certain facilities (5).

Ryang et al., in their study that compares 3D fluoroscopy supported navigation systems with the $\mathrm{FH}$ technique, state that vertebrae pathologies differ for each patient (20). Thereby, the applied training of similar vertebrae pathologies is limited by the nature of vertebrae pathologies. The 3D models used in this study are expected to remove the negative effect of anatomical variations and pathologies, since the models are identical and non-pathological.

In this study, AR contributions to relatively rare and difficult procedures, such as Hangman's fracture (C2-C3 listhesis) fixation, were researched. Nevertheless, the vertebra model was created from a non-pathological CT scan. To independently compare AR contributions to pedicle screw safety ratios, we chose normal anatomy for the vertebra models since the screw fixation is done after the reduction and traction processes (22).

The 3D-printed model's parameters (Table I) were arranged by pre-studies (including feedback from experienced neurosurgeons) to produce the most realistic vertebral bone structure. The consistency of the results with previous studies regarding $A R$ and navigation studies $(5,15,19,20)$ indicates that the produced 3D vertebrae model can be a good experimental material. These models can contribute to applied training of spinal surgery.

The cervical vertebra segment was the focus of this study due to fixation difficulty and rarity. Thereby, the AR contributions to FH techniques are better observed. Nevertheless, according to our findings, 3D printed vertebra models may be used for all vertebra segments in experimental and educational purposes.

The findings of the study unfortunately do not include a cadaver study. Nevertheless, the comparison of $\mathrm{FH}$ technique and $\mathrm{AR}$ supported $\mathrm{FH}$ technique in a single environment (3D-printed model), creates a controlled experimental area to research certain variables such as PS safety ratios and PS grading. On the other hand, the lack of comparison between navigation systems and fluoroscopic control systems is also a limitation of this study. New studies should provide findings with similar cadaver and/or animal studies to research navigation systems for $3 \mathrm{D}$ vertebrae model reliability in the future.

In our study, a spinal surgery education environment was provided for ten candidates. Rivkin and Yocom detected their success rate increased linearly when they analysed the reviews after each of 15 patients comparing CT navigation effects in 270 patients (19). This result indicates that the effect of navigation systems and learning can change the study results. In the study by Elmi-Terander et al. (5), to decrease the effect of learning, 94 screws were applied by two surgeons to compare ultrasound and AR; it was shown that an AR supported system is significantly more successful. However, the process increases the chance for surgeons to become familiar with the environment (19). For this reason, each candidate only applied three to four screws in our study. 


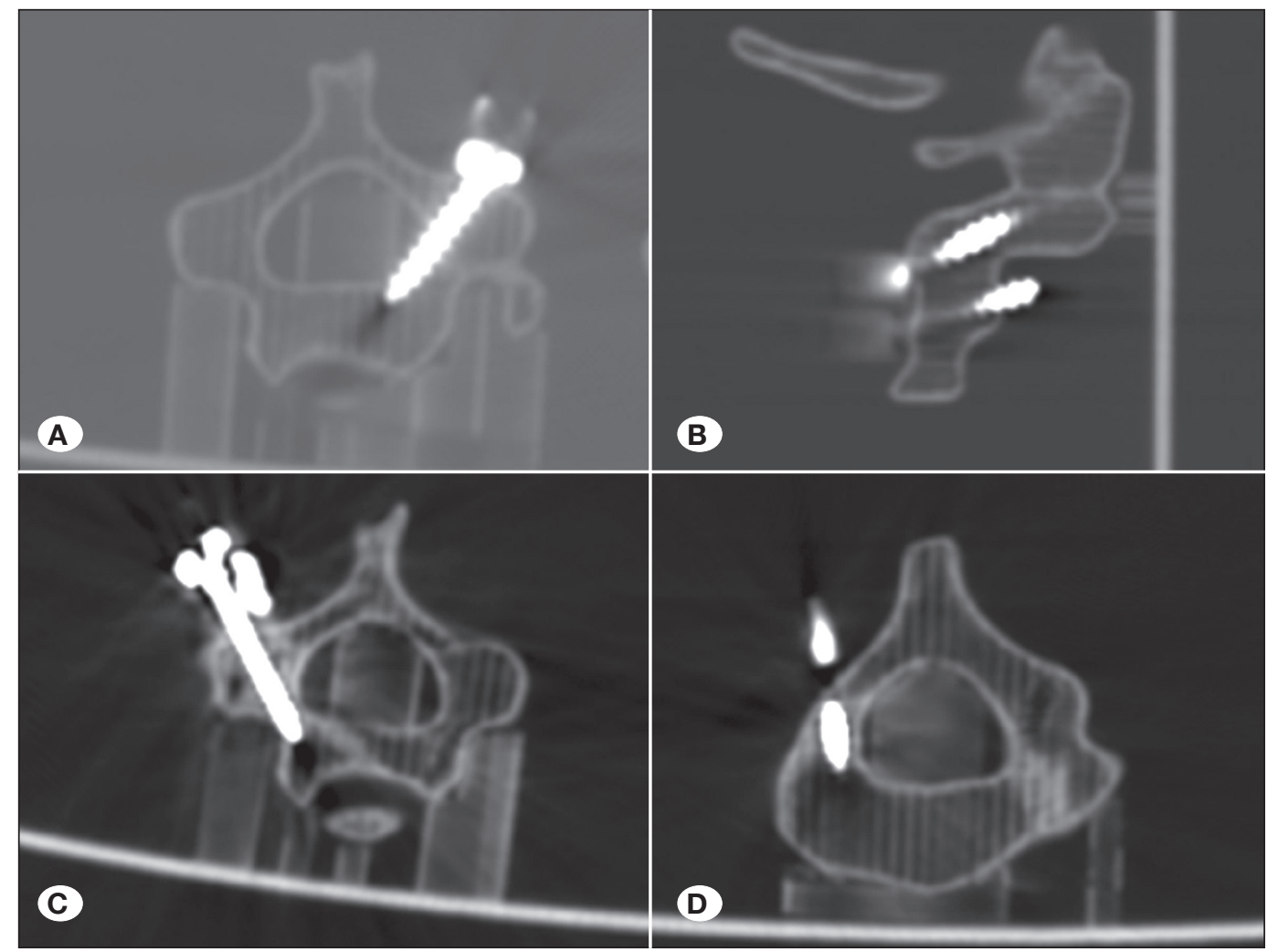

Figure 5: A) Axial CT image of Group 1 (FH Group) C2 pedicle screw, malpositioned $>2 \mathrm{~mm}$ medially. This was a Gertzbein Grade 3 malposition.

B) Sagittal CT image of Group 2 (AR Group) C2 pedicle screw, Gertzbein Grade 0 appropriate angle; C3 pedicle screw, Grade 3 malposition laterally. C) Group 2 (AR Group) C2 pedicle screw, accepted Gertzbein Grade 1 malposition laterally. D) Group 2 (AR Group) C3 pedicle screw, accepted Gertzbein Grade 0 accurate. AR, Augmented Reality; FH, Free hand.
The size of the tracker was observed as the main limitation in our study. When the QR code's minimal pixel ratio is considered, the printed QR code's size should not be smaller than its own pixel architecture on a 2D material such as paper. However, the tracker material limitation in this study does not indicate the limitation of AR systems, since there are a wide range of choices to create a tracker material other than in 2D environments. Nonetheless, 2D tracker material, which has limited size options, is a simple, inexpensive, and reliable tracker choice. We hope that future studies regarding AR applications will not only have smaller size options, but also have new tracker options, such as 3D created tracker materials and identification of tissues without an external apparatus.

The vertebral column's flexibility was recorded as another limitation of our study. Pre-operative CT scans, which are used to arrange trajectory points for pedicle screws, are performed in the supine position; however, spinal instrumentation surgeries are performed prone. During spine surgery, the intervertebral relationship differs from the pre-operative CT images following the reduction process. A single vertebra is rigid, despite the whole vertebral column's flexibility, as stated by $\mathrm{Ma}$ et al. (14). Therefore, the fixation angles and planes of each vertebrae were designed separately in the AR system in our study, instead of by intervertebral relationship. Nevertheless, separate trackers and calibration methods will be required for each vertebra for better results in future studies.

\section{CONCLUSION}

Increasing the success rates of difficult surgical procedures with supportive systems that are guided by technology, will increase patient health and quality of life. Nevertheless, the surgeon's skill is the most important parameter of successful operations. Therefore, surgical education is the key to successful surgeries. Future studies should introduce technological innovations to surgical education and focus on standardising surgical education and enhancing its quality.

\section{ACKNOWLEDGEMENTS}

We would like to thank Afyon Kocatepe University Faculty of Medicine Scientific Research Methods Commission, Afyon Kocatepe University Biomedical Engineering Laboratory staff: Ali Gun and Aslihan Sahan; Afyonkarahisar Health Sciences University Faculty of Medicine Students: Yuksel Ozturk, Huseyin Calısir, Abdulkadir Camli, Veli Eroglu; Afyonkarahisar Health Sciences University Neurosurgery trainees: Necmettin Coban, Lokman Ozturk, and Kamil Anil Kilic for their contributions to the study.

\section{REFERENCES}

1. Anitha R, Arunachalam S, Radhakrishnan P: Critical parameters influencing the quality of prototypes in fused deposition modelling. J Mater Process Technol 118:385-388, 2001 
Boyaci MG. et al: Augmented Reality \& Transpedicular Fixation

2. Bydon M, Mathios D, Macki M, De la Garza-Ramos R, Aygun N, Sciubba DM, Witham TF, Gokaslan ZL, Bydon A, Wolinksy JP: Accuracy of $\mathrm{C} 2$ pedicle screw placement using the anatomic freehand technique. Clin Neurol Neurosurg 125:2427, 2014

3. Chang G, Morreale P, Medicherla P: Applications of augmented reality systems in education. In: Gibson D, Dodge B (eds), Proceedings of SITE 2010-Society for Information Technology \& Teacher Education International Conference. San Diego, CA: Association for the Advancement of Computing in Education (AACE), 2010:1380-1385

4. Dalbayrak S, Yilmaz M, Firidin M, Naderi S: Traumatic spondylolisthesis of the axis treated with direct $\mathrm{C} 2$ pars screw. Turk Neurosurg 19:163-167, 2009

5. Elmi-Terander A, Skulason H, Soderman M, Racadio J, Homan $R$, Babic D, van der Vaart N, Nachabe R: Surgical navigation technology based on augmented reality and integrated $3 D$ intraoperative imaging: A spine cadaveric feasibility and accuracy study. Spine 41:E1303-E1311, 2016

6. Erturk M, Sengul G: C7 vertebra anatomy as a guide for transpedicular screw fixation. Med J 21:121-124, 2006

7. Gertzbein SD, Robbins SE: Accuracy of pedicular screw placement in vivo. Spine 15:11-14, 1990

8. Guo F, Dai J, Zhang J, Ma Y, Zhu G, Shen J, Niu G: Individualized 3D printing navigation template for pedicle screw fixation in upper cervical spine. PloS One 12: e0171509, 2017

9. Hott JS, Deshmukh VR, Klopfenstein JD, Sonntag VK, Dickman CA, Spetzler RF, Papadopoulos SM: Intraoperative Iso-C C-arm navigation in craniospinal surgery: The first 60 cases. Neurosurgery 54:1131-1136, 2004

10. Kaneyama S, Sugawara T, Sumi M, Higashiyama N, Takabatake M, Mizoi K: A novel screw guiding method with a screw guide template system for posterior C-2 fixation. J Neurosurg-Spine 21:231-238, 2014

11. Kotil K, Bilge T: Accuracy of pedicle and mass screw placement in the spine without using fluoroscopy: A prospective clinical study. Spine J 8:591-596, 2008

12. Li C, Cai Y, Wang W, Sun Y, Li G, Dimachkieh AL, Tian W, Sun $R$ : Combined application of virtual surgery and $3 D$ printing technology in postoperative reconstruction of head and neck cancers. BMC Surg 19: 182, 2019

13. Liu H, Wu J, Tang Y, Li H, Wang W, Li C, Zhou Y: Percutaneous placement of lumbar pedicle screws via intraoperative CT image-based augmented reality-guided technology. J Neurosurg-Spine 1:1-6, 2019

14. Ma L, Zhao Z, Chen F, Zhang B, Fu L, Liao H: Augmented reality surgical navigation with ultrasound-assisted registration for pedicle screw placement: A pilot study. Int J Comput Assist Radiol Surg 12 2205-2215, 2017

15. Madhavan K, Kolcun JPG, Chieng LO, Wang MY: Augmentedreality integrated robotics in neurosurgery: Are we there yet? Neurosurg Focus 42:E3, 2017
16. Mikhail M, Mithani K, Ibrahim GM: Presurgical and intraoperative augmented reality in neuro-oncologic surgery: Clinical experiences and limitations. World Neurosurg 128:268-276, 2019

17. Mueller CA, Roesseler L, Podlogar M, Kovacs A, Kristof RA: Accuracy and complications of transpedicular C2 screw placement without the use of spinal navigation. Eur Spine $\mathrm{J}$ 19: $809-814,2010$

18. Nazki FH, Sameer AS, Ganaie BA: Folate: Metabolism, genes, polymorphisms and the associated diseases. Gene 533:1120, 2014

19. Rivkin MA, Yocom SS: Thoracolumbar instrumentation with CT-guided navigation (O-arm) in 270 consecutive patients: Accuracy rates and lessons learned. Neurosurg Focus 36:E7, 2014

20. Ryang YM, Villard J, Obermüller T, Friedrich $B$, Wolf $P$, Gempt J, Ringel F, Meyer B: Learning curve of 3D fluoroscopy imageguided pedicle screw placement in the thoracolumbar spine. Spine J 15:467-476, 2015

21. Schaefer C, Begemann P, Fuhrhop I, Schroeder M, Viezens L, Wiesner L, Hansen-Algenstaedt N: Percutaneous instrumentation of the cervical and cervico-thoracic spine using pedicle screws: Preliminary clinical results and analysis of accuracy. Eur Spine J 20:977-985, 2011

22. Singh PK, Verma SK, Garg M, Sawarkar DP, Kumar A, Agrawal D, Chandra SP, Kale SS, Sharma BS, Mahapatra AK: Evaluation of correction of radiologic parameters (angulation and displacement) and accuracy of $\mathrm{C} 2$ pedicle screw placement in unstable Hangman's fracture with intraoperative computed tomography-based navigation. World Neurosurg 107:795-802, 2017

23. Starosolski ZA, Kan JH, Rosenfeld SD, Krishnamurthy R, Annapragada A: Application of 3-D printing (rapid prototyping) for creating physical models of pediatric orthopedic disorders. Pediatr Radiol 44: 216-221, 2014

24. Tian NF, Huang QS, Zhou P, Zhou Y, Wu RK, Lou Y, Xu HZ: Pedicle screw insertion accuracy with different assisted methods: a systematic review and meta-analysis of comparative studies. Eur Spine J 20: 846-859, 2011

25. Tian W, Weng C, Liu B, Li Q, Hu L, Li ZY, Liu YJ, Sun YZ: Posterior fixation and fusion of unstable Hangman's fracture by using intraoperative three-dimensional fluoroscopy-based navigation. Eur Spine J 21: 863-871, 2012

26. Zhang G, Yu Z, Chen X, Chen X, Wu C, Lin Y, Huang W, Lin $\mathrm{H}$ : Accurate placement of cervical pedicle screws using 3D-printed navigational templates: An improved technique with continuous image registration. Orthopade 47:428-436, 2018

27. Zhou F, Duh HBL, Billinghurst M: Trends in augmented reality tracking, interaction and display: A review of ten years of ISMAR. In: Proceedings of the 7th IEEE/ACM International Symposium on Mixed and Augmented Reality. Cambridge: IEEE Computer Society, 2008:193-202 